\title{
Simvastatin modulates gingival cytokine and MMP production in a rat model of ligature-induced periodontitis
}

This article was published in the following Dove Press journal:

Clinical, Cosmetic and Investigational Dentistry

15 May 2017

Number of times this article has been viewed

\author{
José Carlos Elias \\ Mouchrek Júnior' \\ Cristina Gomes Macedo ${ }^{2}$ \\ Henrique Ballassini Abdalla ${ }^{2}$ \\ Ana Karina Saba' \\ Lucas Novaes Teixeira' \\ Adriana Quinzeiro e Silva \\ Mouchrek $^{3}$ \\ Marcelo Henrique \\ Napimoga' \\ Juliana Trindade \\ Clemente-Napimoga' \\ Alvaro Henrique Borges ${ }^{4}$ \\ Mateus Rodrigues Tonetto ${ }^{4}$ \\ Shelon Cristina \\ Souza Pinto 5 \\ Matheus Coelho Bandeca ${ }^{3}$ \\ Elizabeth Ferreira Martinez' \\ 'Laboratory of Cell and Molecular \\ Biology, São Leopoldo Mandic Institute \\ and Research Center, Campinas, \\ ${ }^{2}$ Physiological Sciences, Piracicaba \\ Dental School, University of Campinas, \\ Campinas, São Paulo, ${ }^{3}$ Department of \\ Dentistry, CEUMA University, São Luis, \\ Maranhão, ${ }^{4}$ Department of Integrated \\ Dental Science, University of Cuiaba, \\ Cuiabá, Mato Grosso, ${ }^{5}$ Department \\ of Dentistry, Ponta Grossa State \\ University, Ponta Grossa, Paraná, Brazil
}

Correspondence: Matheus Coelho Bandeca

CEUMA University, Rua Josue Montello,

Número 0I, 65075-I20, São Luis,

Maranhão, Brazil

Tel +55 9832144127

Email mbandeca@gmail.com
Purpose: The aim of this study was to evaluate the effect of simvastatin on the synthesis of cytokines TNF- $\alpha$ and IL-10 and metalloproteinase (MMPs) 2 and 9 in a rat model of ligatureinduced periodontitis.

Materials and methods: Twenty Wistar rats were used, and a cotton ligature was place in a subgingival position encircling the entire cervix of the first molar of the left (ipsilateral) side of the mandible. The right (contralateral) side of the mandible had no ligature placed and was used as control. After the ligature placement, animals were randomly assigned to two experimental groups ( $\mathrm{n}=10$ ): 1 ) rats with ligature + vehicle (saline; $10 \mathrm{~mL} / \mathrm{kg}$; orally) and 2) rats with ligature $+\operatorname{simvastatin}(25 \mathrm{mg} / \mathrm{kg}$; orally). After 14 days of treatment, the animals were euthanized by anesthetic overdose and the gingival tissue was removed and homogenized in appropriate buffer. MMP-2 and - 9 release as well as the IL-10 and TNF- $\alpha$ levels were detected by enzyme-linked immunosorbent assay. Statistical comparison was performed by unpaired Student's $t$-test, with $p<0.05$ representing significance.

Results: No differences were observed for TNF- $\alpha$ production between the groups $(p>0.05)$. However, IL-10 was upregulated in simvastatin-treated animals (1.8-fold increase) in comparison with the vehicle-treated group $(p<0.05)$. Simvastatin reduced the gingival levels of MMP-9 $(64.3 \%)$ in comparison with vehicle-treated samples $(p<0.05)$.

Conclusion: Oral treatment with simvastatin increased the release of IL-10 and reduced the MMP-9 in ligature-induced periodontitis model in rats.

Keywords: cytokines, metalloproteinases, periodontal disease, simvastatin

\section{Introduction}

Periodontitis is an inflammatory disease of the dental supporting tissues that leads to bone destruction and tooth loss. Its severe form affects $\sim 11 \%$ of the adult population worldwide (reviewed by Kassebaum et $\mathrm{al}^{1}$ and Richards ${ }^{2}$ ). It is now known that the underlying tissue damage observed in this disease results from an excessive immune response to subgingival pathogens. ${ }^{3}$ Different inflammatory components have been suggested to participate in this response, including cytokines and metalloproteinases (MMPs). ${ }^{4,5}$

Abnormal recognition of bacterial products leads to the activation of resident cells such as fibroblasts and dendritic cells, in addition to promoting cell (neutrophils and mononuclear cells) influx in to the gums, triggering an ongoing scenario of inflammation the tissue. ${ }^{4,5}$ Innate immunity cytokines (TNF- $\alpha$, IL-1, and IL-6) are then produced, which amplify the inflammation by increasing cell migration via upregulation of adhesion molecules and inflammatory mediators, promoting bone resorption 
and contributing to tooth loss. ${ }^{4}$ Also, as a result of cytokine generation, an increase in MMPs is noted. MMPs comprise a group of proteases that target the extracellular matrix and are associated with remodeling of the soft and mineralized periodontal tissues. ${ }^{5}$ As the disease progresses, another cytokine, IL-10, is released into the gum by activated T-cells and macrophages. ${ }^{4}$ IL-10 is produced in an attempt to counteract the inflammatory response and is known to trigger the expression of molecules that downregulate the transcription of proinflammatory cytokines and MMPs.,

Current treatment of periodontitis includes surgical and nonsurgical (systemic or local antibiotics) procedures. ${ }^{6}$ Side effects, dysbiosis of gut microbiota, and increased bacterial resistance to antibiotic therapy have raised concerns regarding its use to treat periodontitis. ${ }^{6}$ On the other hand, the recent knowledge on the inflammatory pathways involved in this disease has unleashed novel venues for therapy, with increased attention to strategies that modulate the inflammatory response. ${ }^{7}$ Recently, an anti-inflammatory effect was suggested for antihypertensive drugs (angiotensin II receptor blockers, angiotensin-converting enzyme inhibitors, $\beta$-blockers) in periodontitis. ${ }^{8,9}$ More recently, the cholesterollowering drug simvastatin, used as adjuvant in hypertensive patients with dyslipidemia, was suggested to have a protective effect against experimental ${ }^{10,11}$ and human periodontitis., ${ }^{9,12}$ This effect was attributed to its capacity to reduce bone loss and modulate the expression/release of inflammatory markers in gingival crevicular fluid samples.

Herein, this study evaluated the effect of simvastatin on the synthesis of cytokines TNF- $\alpha$ and IL-10 and the MMPs 2 and 9 in a rat model of ligature-induced periodontitis. We found that this drug is able to increase the levels of IL-10 while reducing MMP-9 expression in gingival tissue samples.

\section{Materials and methods}

\section{Animals}

Twenty nonfasted, outbred male Wistar rats $(\sim 250 \mathrm{~g})$ were used. Rats were obtained from the Centro Multidisciplinar para Investigação Biológica na Área da Ciência em Animais de Laboratório (Campinas, Brazil), and experiments were performed in the biological service unit of the University of Campinas. Animals were kept $(n=5 /$ cage) in a climatically controlled environment (room temperature of $22^{\circ} \mathrm{C} \pm 2{ }^{\circ} \mathrm{C}$ and humidity of around 60\%) under 12:12 hour light-dark cycle). This study and all procedures were approved by the Ethics Committee of the University of Campinas and carried out in accordance with the guidelines of the Brazilian Society for Animal Welfare (SBCAL).

\section{Ligature-induced periodontitis}

Briefly, animals were anaesthetized with a single intramuscular injection of ketamine $(90 \mathrm{mg} / \mathrm{kg}$; Dopalen, Ceva, Brazil) and xylazine (10 mg/kg; Rompun, Bayer, Brazil). Periodontitis was then induced as previously described by Branco-de-Almeida et al, ${ }^{13}$ with minor modifications. For this, a cotton ligature was placed in a subgingival position encircling the entire cervix of both sides of the first molar on the left (ipsilateral) side of the mandible. In order to immobilize the ligature, two knots were made at the mesial aspect of the first molar. The right (contralateral) side of the mandible had no ligature placed and was used as the control.

Disease was allowed to develop for 14 days, and then the rats were euthanized by anesthetic overdose. Gingival tissue samples were collected from the mandibular first molar regions, immediately frozen, and kept at $-80^{\circ} \mathrm{C}$ for further analysis. In order to confirm the establishment of periodontal disease, contralateral and ipsilateral mandibular alveolar bone specimens were collected at day 14 and submitted to macroscopic and histologic analysis. For macroscopic analysis, mandibles were immersed in sodium hypoclorite $1 \%$ solution for 4 hours and the whole remaining bone soft tissue was mechanically removed. The pieces were stained with methylene blue $(1 \mathrm{~g} / 100 \mathrm{~mL})$ for 1 minute to delimit the cement-enamel junction. For histological analysis, the mandibles were fixed in $10 \%$ neutral buffered formalin and then demineralized in 5\% formic acid for 7 days. $7 \mu \mathrm{m}$ sections from the decalcified bone were stained with hematoxylin and eosin staining and evaluated to confirm bone loss.

\section{Treatment with simvastatin}

After ligature placement, animals were randomly assigned to two experimental groups ( $\mathrm{n}=10$ animals/group): 1) rats with ligature + vehicle (saline; $10 \mathrm{~mL} / \mathrm{kg}$; orally) and 2) rats with ligature + simvastatin $(25 \mathrm{mg} / \mathrm{kg}$; orally). Simvastatin (Sigma-Aldrich, St. Louis, MO, USA) was dissolved in saline. Either saline or simvastatin were administered for 14 days following periodontitis induction.

\section{Histologic analysis of the mandible}

Ipsilateral mandible samples were immediately fixed in $10 \%$ neutral buffered formalin for 24 hours, washed $3 \times$ in phosphate-buffered saline, and then stained with $1 \%$ methylene blue. ${ }^{11}$ Bone loss was evaluated in both contralateral and ipsilateral sides by comparison of digital images. 


\section{Sample preparation}

Gingival tissue samples were homogenized in $300 \mu \mathrm{L}$ of RIPA lysis buffer (Santa Cruz Biotechnology, Dallas, TX, USA) and then centrifuged for 10 minutes at $10,000 \mathrm{rpm}$ at $4^{\circ} \mathrm{C}$. The supernatants were collected and used for evaluation of cytokine (TNF $\alpha$ and IL-10) and MMP (MMP-2 and 9) levels.

\section{Tissue cytokine and MMP levels}

Gingival TNF- $\alpha$, IL-10, MMP-2, and MMP-9 levels were evaluated by using commercially available kits (R\&D Systems, Minneapolis, MN, USA) according to the manufacturer's instructions. Results are expressed as picogram per milliliter $(\mathrm{pg} / \mathrm{mL})$.

\section{Data analysis}

The results are presented as the mean \pm standard deviation for the animals. The percentage of inhibition is reported as the mean \pm standard deviation for each individual experiment. Statistical comparison was performed using unpaired Student's $t$-test in GraphPad Prism 6.0 (GraphPad Software, Inc., La Jolla, CA, USA). $p<0.05$ was considered significant.

\section{Results}

Figure 1 shows the bone integrity of both the contralateral and ipsilateral sides of the mandible. The ipsilateral (ligature; Figure 1B), but not the contralateral (Figure 1A) side, presented loss of the alveolar crest (black arrow), indicating the successful induction of periodontitis in the tested rats. In addition, the histological analysis demonstrated an inflammatory cell infiltration with cementum and alveolar process destruction confirming the periodontitis (ligature, Figure 1D). In contrast, the contralateral side showed a normal periodontium (Figure 1C).

The levels of TNF- $\alpha$ and IL-10 were evaluated in gingival tissue samples with established periodontitis obtained from vehicle- and simvastatin-treated rats. No differences were observed for TNF- $\alpha$ production between the groups (Figure 2A). However, IL-10 was upregulated in simvastatintreated animals (1.8-fold increase) in comparison with those of the vehicle-treated group (Figure 2B).

Gingival levels of MMP-2 and -9 were measured in samples obtained from vehicle- and simvastatin-treated rats. MMP-2 levels were similar in vehicle and simvastatin gingival samples (Figure 3A). Oral treatment with simvastatin reduced the gingival levels of MMP-9 (64.3\%) in comparison with vehicle-treated samples (Figure 3B).

\section{Discussion}

Gingival inflammation triggered by bacteria is a hallmark of periodontitis and progressively leads to bone resorption

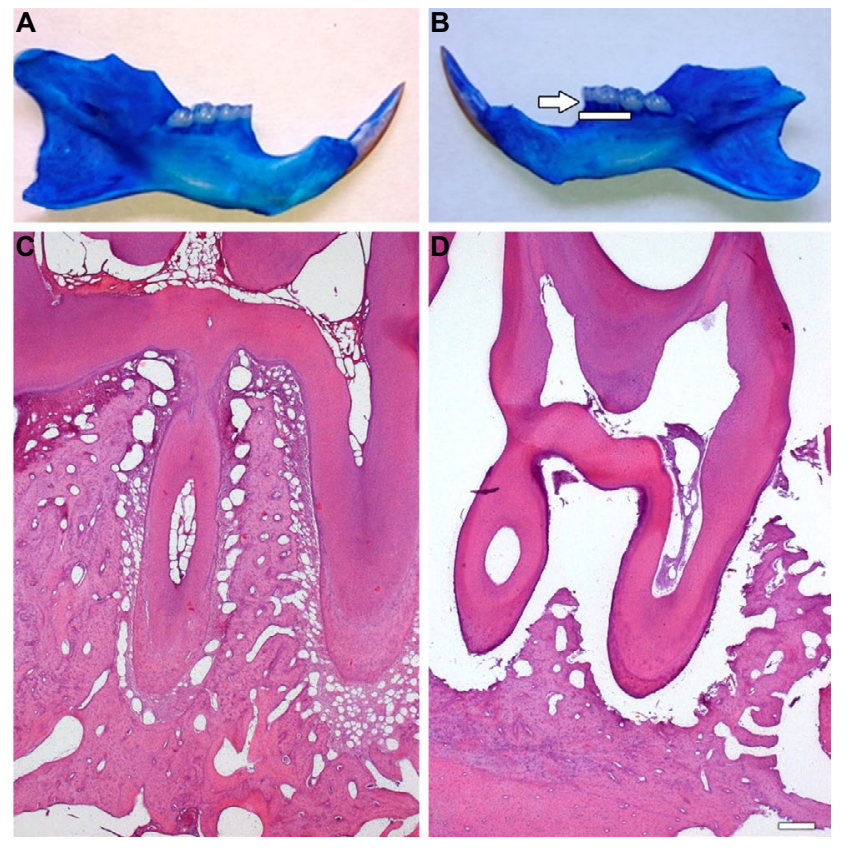

Figure I Macroscopic and histology analysis of the mandible.

Notes: Contralateral (A, C) and ipsilateral (B, D) sides of the mandible in animals with ligature-induced periodontitis treated with vehicle (saline, $10 \mathrm{~mL} / \mathrm{kg}$, orally, 14 days, once a day). Disease was induced in the ipsilateral molar region. Contralateral (nonligated) mandibles were used as controls. Samples were collected at 14 days after periodontitis induction. The arrow indicates loss of alveolar crest, suggestive of bone loss (B). The histological analysis shows inflammatory cell infiltration with cementum and alveolar process destruction confirming the periodontitis (D).

and tooth loss. ${ }^{14}$ A plethora of cells and inflammatory mediators are involved in this process, leading to the higher production of proinflammatory molecules such as TNF and MMPs, accounting for disease progression. ${ }^{15}$ Nonsurgical treatment of periodontitis is currently used in to the clinics and is primarily based on administration of either systemic or local antibiotics. ${ }^{6}$ Increased bacterial resistance to the therapy, in addition to its side effects, ${ }^{16}$ has lead to the search for novel therapeutic approaches. The increased knowledge on the inflammatory pathways involved in periodontitis has prompted the investigation of the effects of anti-inflammatory drugs as strategies to reduce gingival inflammation. ${ }^{16}$ Recent studies have suggested that cholesterol-lowering drugs such as simvastatin are protective against experimental ${ }^{2,4,17}$ and human periodontitis. ${ }^{18,19}$ These evidences have suggested that simvastatin is able to reduce bone loss and modulate the expression/release of inflammatory markers in gingival crevicular fluid samples. However, little is known of simvastatin effects on the gingival tissue itself. Herein, we provided data that this drug modulated inflammation in the gingival tissue of animals with experimental periodontitis induced by ligature placement. 

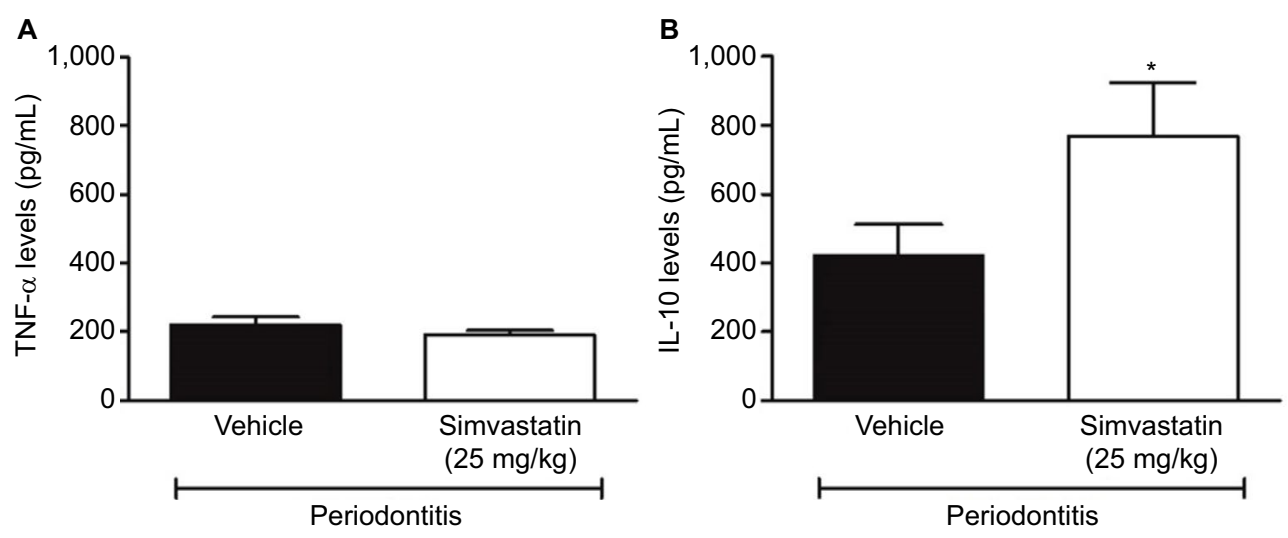

Figure 2 Effect of simvastatin on the gingival tissue levels of TNF- $\alpha$ and IL- 10 .

Notes: Levels of (A) TNF- $\alpha$ and (B) IL- 10 in ipsilateral gingival tissue samples obtained from rats with ligature-induced periodontitis. Animals received either vehicle (saline; $10 \mathrm{~mL} / \mathrm{kg}$ ) or simvastatin $(25 \mathrm{mg} / \mathrm{kg})$, orally for 14 days, once a day. Samples were collected at 14 days after periodontitis induction. Data are expressed as mean \pm SD. $* p<0.05$, differs from the vehicle-treated group.

Abbreviation: SD, standard deviation.
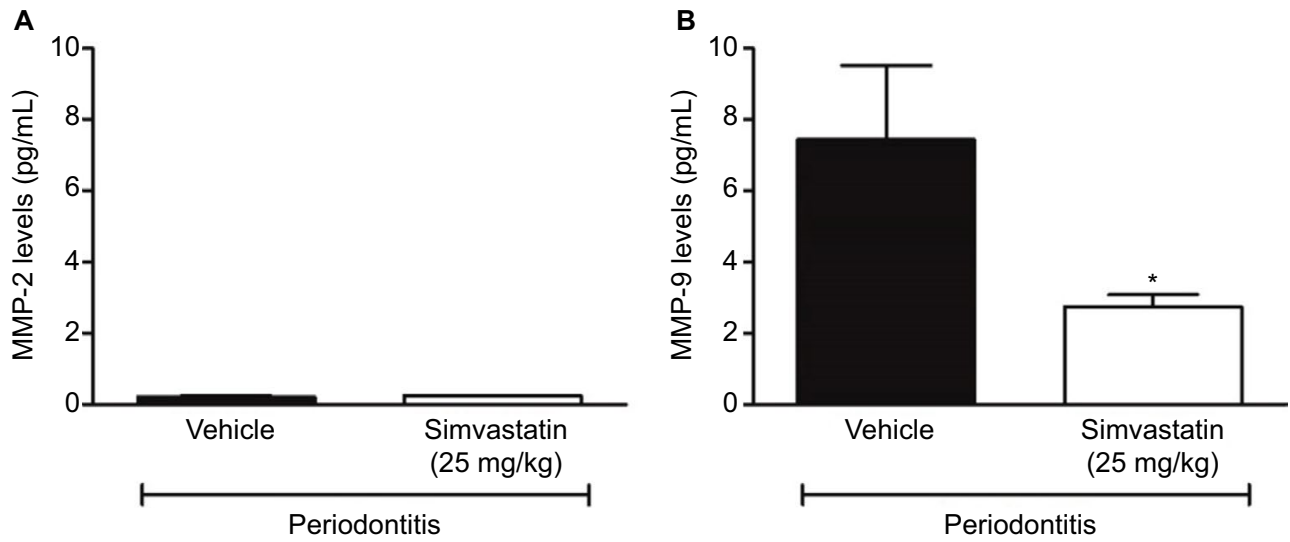

Figure 3 Effect of simvastatin on the gingival tissue levels of MMP-2 and 9.

Notes: Levels of (A) MMP-2 and (B) MMP-9 in ipsilateral gingival tissue samples obtained from rats with ligature-induced periodontitis. Animals received either vehicle (saline; $10 \mathrm{~mL} / \mathrm{kg}$ ) or simvastatin $(25 \mathrm{mg} / \mathrm{kg}$ ), orally for 14 days, once a day. Samples were collected at 14 days after periodontitis induction. Data are expressed as mean \pm SD. ${ }^{*} p<0.05$, differs from the vehicle-treated group.

Abbreviations: MMP, metalloproteinase; SD, standard deviation.

This study initially investigated the levels of cytokines in gingival tissue samples obtained from animals with established periodontitis. TNF- $\alpha$ is well known for its involvement in inflammatory disorders, contributing to inflammation and pain, and plays a leading role in bone resorption in periodontitis. ${ }^{20}$ Indeed, this inflammatory mediator is one of the detrimental factors for disease progression as it stimulates osteoclast activity by inducing RANKL production, in addition to MMP production. ${ }^{17,21}$ Simvastatin was previously suggested to inhibit TNF$\alpha{ }^{12}$ This study found that simvastatin does not affect TNF- $\alpha$ production at 14 days after disease induction, as animals treated with this drug exhibited similar levels of this mediator in their gingival samples to those of the vehicle-treated group. However, Fentoglu et $\mathrm{a}^{22}$ demonstrated that simvastatin inhibits TNF $\alpha$ release in to the gum when administered for 3 months in vivo; this suggests that in order to modulate this cytokine, simvastatin may have to be taken for longer periods than assessed in our study. Also, we cannot overrule the possible modulatory effects of this drug on the release of other proinflammatory cytokines in our model. Indeed, recent studies showed that simvastatin anti-inflammatory effects are also related to its ability to reduce IL-1 $\beta$ and IL-6 levels and to increase the anti-inflammatory cytokine IL-10. ${ }^{4}$ Studies in IL-10 knockout mice showed that these mice present with higher osteoclast activity and bone loss, ${ }^{23}$ and this has been linked to increased RANKL expression. ${ }^{24}$ Here, simvastatin increased the gingival release of IL-10, reinforcing its protective effects in periodontitis.

MMPs, proteases that target the extracellular matrix, are released by infiltrating inflammatory cells such as macrophages and fibroblasts residing in the gum, and they 
are associated with remodeling of the soft and mineralized periodontal tissues. ${ }^{1}$ Their expression is known to be regulated by cytokine production in periodontitis ${ }^{4,5}$ and other chronic diseases in which tissue destruction occurs. ${ }^{1} M M P$ gene polymorphisms have been recently linked to periodontitis susceptibility. ${ }^{25}$ Our data show that simvastatin reduced gingival MMP-9 but did not affect MMP-2 levels in samples with established periodontitis. An inhibitory effect on MMP expression was previously shown for simvastatin. This drug was found to decrease MMP-9 mRNA expression in gingival tissue samples from rats with periodontitis induced by Aggregatibacter actinomycetemcomitans LPS, and a similar effect was observed when simvastatin was incubated in vitro with human leukemia cells. ${ }^{26}$ Also, patients treated with simvastatin present with lowered levels of circulating MPP- $9{ }^{27}$ and reduced expression of this molecule in aortic wall samples. ${ }^{28}$ The effects of simvastatin on MMP-2 have been shown to be rather controversial, with some reports suggesting inhibition of this molecule by simvastatin ${ }^{29}$ and others suggesting a lack of effect for this drug on this pathway. ${ }^{26,30}$ It is possible though that MMP regulation by simvastatin differs according to the disease model investigated. In the case of periodontitis, MPP-2 has been linked with asymptomatic apical disease, while MMP-9 is associated with chronic gingival inflammation. ${ }^{31}$

\section{Conclusion}

Overall, our data showed that simvastatin may be useful for treating gingival inflammatory conditions, and more specifically, periodontal disease, as repeated treatment reduces MMP-9 levels while increasing IL-10 release into the inflamed gum. We suggest simvastatin be used as an aid therapy for chronic inflammatory diseases in which bone resorption occurs.

\section{Acknowledgments}

The authors would like to thank CAPES (Coordination for Supporting and Development Superior Education Personnel), FAPEMA (State of Maranhão Research Agency), UNICEUMA (CEUMA University), SLMANDIC (São Leopoldo Mandic Institute), and UNICAMP (University of Campinas) for their support.

\section{Disclosure}

The authors report no conflicts of interest in this work.

\section{References}

1. Kassebaum NJ, Bernabe E, Dahiya M, Bhandari B, Murray CJ, Marcenes W. Global burden of severe periodontitis in 1990-2010: a systematic review and meta-regression. J Dent Res. 2014;93(11):1045-1053.

2. Richards D. Review finds that severe periodontitis affects $11 \%$ of the world population. Evid Based Dent. 2014;15(3):70-71.
3. Hajishengallis G. The inflammophilic character of the periodontitisassociated microbiota. Mol Oral Microbiol. 2014;29(6):248-257.

4. Di Benedetto A, Gigante I, Colucci S, Grano M. Periodontal disease: linking the primary inflammation to bone loss. Clin Dev Immunol. 2013; 2013:503754.

5. Maciejczyk M, Pietrzykowska A, Zalewska A, Knas M, Daniszewska I. The significance of matrix metalloproteinases in oral diseases. $A d v$ Clin Exp Med. 2016;25(2):383-390.

6. Jepsen K, Jepsen S. Antibiotics/antimicrobials: systemic and local administration in the therapy of mild to moderately advanced periodontitis. Periodontol 2000. 2016;71(1):82-112.

7. Zupancic S, Kocbek P, Baumgartner S, Kristl J. Contribution of nanotechnology to improved treatment of periodontal disease. Curr Pharm Des. 2015;21(22):3257-3271.

8. Rodrigues M, Barbirato D, Luiz RR, Scharfstein J, Salles GF, FeresFilho EJ. Effect of antihypertensive therapy with angiotensin-converting enzyme inhibitors on chronic periodontitis: a case-control study. Oral Dis. 2016;22(8):791-796.

9. Suda N, Moriyama K, Ganburged G. Effect of angiotensin II receptor blocker on experimental periodontitis in a mouse model of Marfan syndrome. Infect Immun. 2013;81(1):182-188.

10. Bradley AD, Zhang Y, Jia Z, et al. Effect of simvastatin prodrug on experimental periodontitis. J Periodontol. 2016;87(5):577-582.

11. Dalcico R, de Menezes AM, Deocleciano OB, et al. Protective mechanisms of simvastatin in experimental periodontal disease. J Periodontol. 2013;84(8):1145-1157.

12. Mullen L, Ferdjani J, Sacre S. Simvastatin inhibits TLR8 signaling in primary human monocytes and spontaneous TNF production from rheumatoid synovial membrane cultures. Mol Med. Epub 2015 Aug 24.

13. Branco-de-Almeida LS, Franco GC, Castro ML, et al. Fluoxetine inhibits inflammatory response and bone loss in a rat model of ligature-induced periodontitis. J Periodontol. 2012;83(5):664-671.

14. Peyret-Lacombe A, Brunel G, Watts M, Charveron M, Duplan H. TLR2 sensing of $\mathrm{F}$. nucleatum and $\mathrm{S}$. sanguinis distinctly triggered gingival innate response. Cytokine. 2009;46(2):201-210.

15. Pollanen MT, Salonen JI, Uitto VJ. Structure and function of the toothepithelial interface in health and disease. Periodontol 2000. 2003;31: $12-31$.

16. Sima C, Van Dyke TE. Therapeutic targets for management of periodontitis and diabetes. Curr Pharm Des. 2016;22(15):2216-2237.

17. Serhan CN, Jain A, Marleau S, et al. Reduced inflammation and tissue damage in transgenic rabbits overexpressing 15-lipoxygenase and endogenous anti-inflammatory lipid mediators. $J$ Immunol. 2003;171(12): 6856-6865.

18. Grover HS, Kapoor S, Singh A. Effect of topical simvastatin $(1.2 \mathrm{mg})$ on gingival crevicular fluid interleukin-6, interleukin-8 and interleukin-10 levels in chronic periodontitis - a clinicobiochemical study. J Oral Biol Craniofac Res. 2016;6(2):85-92.

19. Poston CJ, Pierce TC, Li Y, et al. Statin intake is associated with MMP-1 level in gingival crevicular fluid of patients with periodontitis. Oral Dis. 2016;22(5):438-444.

20. Hienz SA, Paliwal S, Ivanovski S. Mechanisms of bone resorption in periodontitis. J Immunol Res. 2015;2015:615486.

21. Garlet GP, Cardoso CR, Campanelli AP, et al. The dual role of p55 tumour necrosis factor-alpha receptor in Actinobacillus actinomycetemcomitans-induced experimental periodontitis: host protection and tissue destruction. Clin Exp Immunol. 2007;147(1):128-138.

22. Fentoglu O, Koroglu BK, Hicyilmaz H, et al. Pro-inflammatory cytokine levels in association between periodontal disease and hyperlipidaemia. $J$ Clin Periodontol. 2011;38(1):8-16.

23. Sasaki H, Balto K, Kawashima N, et al. Gamma interferon (IFN-gamma) and IFN-gamma-inducing cytokines interleukin-12 (IL-12) and IL-18 do not augment infection-stimulated bone resorption in vivo. Clin Diagn Lab Immunol. 2004;11(1):106-110.

24. Liu KZ, Hynes A, Man A, Alsagheer A, Singer DL, Scott DA. Increased local matrix metalloproteinase-8 expression in the periodontal connective tissues of smokers with periodontal disease. Biochim Biophys Acta. 2006;1762(8):775-780. 
25. Weng H, Yan Y, Jin YH, Meng XY, Mo YY, Zeng XT. Matrix metalloproteinase gene polymorphisms and periodontitis susceptibility: a meta-analysis involving 6,162 individuals. Sci Rep. 2016; 6:24812.

26. Chen YJ, Chang LS. Simvastatin induces NFkappaB/p65 downregulation and JNK1/c-Jun/ATF-2 activation, leading to matrix metalloproteinase-9 (MMP-9) but not MMP-2 down-regulation in human leukemia cells. Biochem Pharmacol. 2014;92(4):530-543.

27. Pradeep AR, Rao NS, Bajaj P, Kumari M. Efficacy of subgingivally delivered simvastatin in the treatment of patients with type 2 diabetes and chronic periodontitis: a randomized double-masked controlled clinical trial. J Periodontol. 2013;84(1):24-31.
28. Evans J, Powell JT, Schwalbe E, Loftus IM, Thompson MM. Simvastatin attenuates the activity of matrix metalloprotease-9 in aneurysmal aortic tissue. Eur J Vasc Endovasc Surg. 2007;34(3):302-303.

29. Li M, Li Z, Sun X. Statins suppress MMP2 secretion via inactivation of RhoA/ROCK pathway in pulmonary vascular smooth muscles cells. Eur J Pharmacol. 2008;591(1-3):219-223.

30. Huang CY, Wu TC, Lin WT, et al. Effects of simvastatin withdrawal on serum matrix metalloproteinases in hypercholesterolaemic patients. Eur J Clin Invest. 2006;36(2):76-84.

31. Baeza M, Garrido M, Hernandez-Rios P, et al. Diagnostic accuracy for apical and chronic periodontitis biomarkers in gingival crevicular fluid: an exploratory study. J Clin Periodontol. 2016;43(1):34-45.
Clinical, Cosmetic and Investigational Dentistry

\section{Publish your work in this journal}

Clinical, Cosmetic and Investigational Dentistry is an international, peer-reviewed, open access, online journal focusing on the latest clinical and experimental research in dentistry with specific emphasis on cosmetic interventions. Innovative developments in dental materials, techniques and devices that improve outcomes and patient satisfac-

\section{Dovepress}

tion and preference will be highlighted. The manuscript management system is completely online and includes a very quick and fair peerreview system, which is all easy to use. Visit http://www.dovepress. com/testimonials.php to read real quotes from published authors. 